Sign In

\title{
All Databases
}

Servicos $9^{\circ}$ NCBI
I Wrote These Publications R

\section{Most Acid-Tolerant Chickpea Mesorhizobia Show Induction of Major Chaperone Genes upon Acid Shock}

Author(s): Brigido, C (Brigido, Clarisse) ${ }^{[1]}$; Oliveira, S (Oliveira, Solange) ${ }^{[1,2]}$

Source: MICROBIAL ECOLOGY Volume: 65 Issue: 1 Pages: 145-153 DOI: 10.1007/s00248-012-0098-7 Published: JAN 2013

Times Cited: 1 (from Web of Science)

Cited References: 50 [view related records ] $5 \times{ }^{\circ}$ Citation Map

Abstract: Our goals were to evaluate the tolerance of mesorhizobia to acid and alkaline conditions as well as to investigate whether acid tolerance is related to the species or the origin site of the isolates. In addition, to investigate the molecular basis of acid tolerance, the expression of chaperone genes groEL and dnaKJ was analyzed using acid-tolerant and sensitive mesorhizobia. Tolerance to $\mathrm{pH} 5$ and 9 was evaluated in liquid medium for 98 Portuguese chickpea mesorhizobia belonging to four species clusters. All isolates showed high sensitivity to $\mathrm{pH} 9$. In contrast, mesorhizobia revealed high diversity in terms of tolerance to acid stress: $35 \%$ of the isolates were acid sensitive and $45 \%$ were highly tolerant to $\mathrm{pH} 5$ or moderately acidophilic. An association between mesorhizobia tolerance to acid conditions and the origin soil pH was found. Furthermore, significant differences between species clusters regarding tolerance to acidity were obtained. Ten isolates were used to investigate the expression levels of the chaperone genes by northern hybridization. Interestingly, most acid-tolerant isolates displayed induction of the dnaK and groESL genes upon acid shock while the sensitive ones showed repression. This study suggests that acid tolerance in mesorhizobia is related to the $\mathrm{pH}$ of the origin soil and to the species cluster of the isolates. Additionally, the transcriptional analysis suggests a relationship between induction of major chaperone genes and higher tolerance to acid $\mathrm{pH}$ in mesorhizobia. This is the first report on transcriptional analysis of the major chaperones genes in mesorhizobia under acidity, contributing to a better understanding of the molecular mechanisms of rhizobia acidity tolerance.

Accession Number: WOS:000313369900014

Document Type: Article

Language: English

KeyWords Plus: ROOT-NODULE BACTERIA; CICER-ARIETINUM L; SP-NOV; MOLECULAR CHAPERONES; STREPTOCOCCUS-MUTANS; RHIZOBIUM-LOTI; IN-VIVO; SOIL; PH; STRESS

Reprint Address: Oliveira, $S$ (reprint author)

Univ Evora, Dept Biol, Apartado 94, P-7002554 Evora, Portugal.

Addresses:

[ 1 ] Univ Evora, ICAAM, Lab Microbiol Solo, P-7002554 Evora, Portugal

[ 2 ] Univ Evora, Dept Biol, P-7002554 Evora, Portugal

E-mail Addresses: ismo@uevora.pt

Funding:

\begin{tabular}{|l|l|}
\hline Funding Agency & Grant Number \\
\hline FCT (Fundacao para a Ciencia e a Tecnologia) & \\
\hline EU-FEDER & PTDC/BIO/80932/2006 \\
\hline FCT & SFRH/BD/30680/2006 \\
\hline
\end{tabular}

[Show funding text]

Publisher: SPRINGER, 233 SPRING ST, NEW YORK, NY 10013 USA

Web of Science Categories: Ecology; Marine \& Freshwater Biology; Microbiology

Research Areas: Environmental Sciences \& Ecology; Marine \& Freshwater Biology; Microbiology

IDS Number: 068MD

ISSN: $0095-3628$
Times Cited: 1

Create Citation Alert

This article has been cited 1 times in Web of Knowledge.

Quinlan, Roy A.

Chaperones: needed for both the good times and the bad times.

PHILOSOPHICAL

TRANSACTIONS OF

THE ROYAL SOCIETY

B-BIOLOGICAL

SCIENCES, MAY 52013.

[ view all 1 citing articles ]

\section{Related Records:}

Find similar Web of Knowledge records based on shared references.

[ view related records ]

Cited References: 50

View the bibliography of this record (from Web of Science $\left.{ }^{\circledR}\right)$.

Ex: Citation Map

\section{Additional information}

- View the journal's Table of Contents (in Current Contents Connect ${ }^{\circledR}$ )

- View the journal's impact factor (in Journal Citation Reports ${ }^{\circledR}$ )

View this record in other databases:

- View citation data (in Web of Science $\left.{ }^{\circledR}\right)$

- View most recent data (in Current Contents Connect ${ }^{\circledR}$ )

- View medical data (in MEDLINE ${ }^{\circledR}$ )

\section{Suggest a correction}

If you would like to improve the quality of the data in this record, please suggest a correction. 


\section{Output Record}

Step 1: Select content.

Step 2: Select destination. [Learn about saving to bibliographic software]

Authors, Title, Source

$\checkmark$ Abstract

- Full Record

$\square$ Cited References

$\square$ ENDNOTE' WEB Save to: ENDNOTE' I Wrote These Publications R

Save to other Reference Software

\section{Save}

it (0)

View in: | 简体中文 | 繁體中文 | English | 日本語 | 한국어

๑ 2013 Thomson Reuters | Terms of Use | Privacy Policy | Please give us your feedback on using Web of Knowledge. 